Supporting Information for:

\title{
Faradaic Counter for Liposomes Loaded with Potassium, Sodium Ions, or Protonated Dopamine
}

Linhan Huang, ${ }^{1}$ Jingcheng Zhang, ${ }^{1}$ Zhipeng Xiang, ${ }^{2}$ Di Wu, ${ }^{1}$ Xinjian Huang, ${ }^{3}$ Xizhe Huang, ${ }^{1}$ Zhenxing Liang, ${ }^{2}$ Zhen-Yu Tang, ${ }^{4}$ and Haiqiang Deng ${ }^{1, *}$

${ }^{1}$ School of Chemical Engineering and Technology, Sun Yat-sen University, Zhuhai 519082, China

${ }^{2}$ Key Laboratory on Fuel Cell Technology of Guangdong Province, School of Chemistry and Chemical Engineering, South China University of Technology, Guangzhou 510641, China

${ }^{3}$ Institute of Intelligent Perception, Midea Corporate Research Center, Foshan 528311, China

${ }^{4}$ School of Pharmaceutical Science (Shenzhen), Sun Yat-sen University, Guangzhou 510275, China

*Corresponding author, email: denghq9@ mail.sysu.edu.cn (H. Deng). 


\section{Table of Contents:}

Tables S1 and S2. Pulling parameters for $\sim 600 \mathrm{~nm}$ and $\sim 6 \mu \mathrm{m}$ micropipettes using either a PC-100 puller or a P2000 laser puller (pp. S3).

\section{Cell S-I and Cell S-II (pp. S3).}

Figure S1. Chemical structure of DOPC (pp. S4).

Figure S2. SEM image of either a $\sim 600 \mathrm{~nm}$ or a $\sim 6 \mu \mathrm{m}$ micropipette (pp. S4).

Figure S3. CVs showing no obvious effect from DB18C6 on $\mathrm{Li}^{+}$transfer (pp. S5).

Figure S4. Representative $i-t$ curve for micro-ITIES collisional experiments recorded at $+0.6 \mathrm{~V}$ vs. $\mathrm{Ag} / \mathrm{AgCl}$ with water-loaded liposomes (pp. S5).

Figure S5. Representative $i-t$ curves for micro-ITIES collisional experiments recorded at $+0.6 \mathrm{~V} v \mathrm{vs} . \mathrm{Ag} / \mathrm{AgCl}$ in the absence of liposomes with either (A) $10 \mathrm{mM} \mathrm{KCl}$ or (B) $10 \mathrm{mM} \mathrm{LiCl}$ in the aqueous phase (pp. S6).

Figure S6. CV representing the facilitated $\mathrm{K}^{+}$transfer by DB18C6 (pp. S6).

Figure S7. Representative $i-t$ curve for micro-ITIES collisional experiments recorded at $+0.6 \mathrm{~V}$ vs. $\mathrm{Ag} / \mathrm{AgCl}$ in the presence of potassium-ion contained liposomes with $\alpha, \alpha, \alpha$-trifluorotoluene (TFT) employed as the organic solvent (pp. S7)

Figure S8. Photo of the $5 \mathrm{~mL}$ DCE dissolving with $7 \mathrm{mg}$ of DOPC (pp. S7).

Figure S9. Zeta potential of $\mathrm{K}^{+}$-loaded DOPC liposomes (pp. S8).

Figure S10. CV representing the facilitated $\mathrm{K}^{+}$transfer by DB18C6 with oil-filled micro-ITIES (pp. S8).

Figure S11. Collisions for $\mathrm{K}^{+}$-loaded liposomes at an oil-filled micro-ITIES and DLS comparison (pp. S9).

Figure S12. CV representing the facilitated $\mathrm{Na}^{+}$transfer by DB18C6 (pp. S9).

Figure S13. Typical zoom-in spikes for liposomes loaded with (A) potassium ion and (B) sodium ion (pp. S10).

Figure S14. Representative $i-t$ curves for micro-ITIES collisional experiments recorded at $+0.75 \mathrm{~V} \mathrm{vs.} \mathrm{Ag} / \mathrm{AgCl}$ in the absence of liposomes with either (A) $10 \mathrm{mM} \mathrm{NaCl}$ or (B) $10 \mathrm{mM} \mathrm{LiCl}$ in the aqueous phase (pp. S10).

Figure S15. Histograms of $t_{\text {rise }}$ and $t_{\text {fall }}$ of collisions obtained from different-sized (A) potassium-ion loaded liposomes and (B) sodium-ion loaded liposomes (pp. S11).

Figure S16. CVs representing the simple and facilitated $\mathrm{DAH}^{+}$transfer (pp. S11).

Figure S17. Representative $i-t$ curves for micro-ITIES collisional experiments recorded at $+0.85 \mathrm{~V}$ vs. $\mathrm{Ag} / \mathrm{AgCl}$ in the absence of liposomes with either (A) $10 \mathrm{mM} \mathrm{DAHCl}$ or (B) $10 \mathrm{mM} \mathrm{LiCl}$ in the aqueous phase (pp. S12).

Figure S18. Collisions of DAH ${ }^{+}$-loaded ovalbumin-decorated liposomes and DLS comparison (pp. S12).

Figure S19. More experimental results of observed multiplet events for sodium-ion contained liposomes (pp. S13).

Figure S20. More experimental results of observed (A) singlet, (B) doublet, and (C-D) multiplet events for potassium-ion contained liposomes (pp. S13).

Figure S21. More experimental results of observed (A) singlet, (B) doublet, and (C-E) multiplet events for DAHClcontained liposomes (pp. S14). 
Table S1. Parameters for one-stage pulling $600 \mathrm{~nm}$ inner-diameter (i.d.) micropipettes from borosilicate glass capillaries (outer/inner diameter: $1.0 \mathrm{~mm} / 0.58 \mathrm{~mm}, 10 \mathrm{~cm}$ length) using a PC100 puller (Narishige Instrument, Japan).

No. 1 Heater Level 51
No. of pulling

Table S2. Parameters for pulling $\sim 6 \mu \mathrm{m}$ i.d. short-shank micropipettes from borosilicate glass capillaries (outer/inner diameter: $1.0 \mathrm{~mm} / 0.58 \mathrm{~mm}, 10 \mathrm{~cm}$ length) using a P-2000 laser puller (Sutter Instrument, Novato, CA).

\begin{tabular}{ccccc}
\hline Heat & Filament & Velocity & Pull & Delay \\
\hline 265 & 4 & 26 & 0 & 250 \\
265 & 4 & 26 & 0 & 250 \\
265 & 4 & 26 & 0 & 250 \\
265 & 4 & 22 & 0 & 250 \\
\hline
\end{tabular}

Cell S-I: Ag| AgCl|20 mM DB18C6 + 5 mM BATB + DCE (inside the micropipette) $\| 10$ $\mathrm{mM} \mathrm{LiCl}+181 \mathrm{pM}$ liposomes (hydrated by $10 \mathrm{mM} \mathrm{KCl}$ ) $|\mathrm{AgCl}| \mathrm{Ag}$

Cell S-II: $\mathrm{Ag}|\mathrm{AgCl}| 0.5 \mathrm{mM}$ DB18C6 + $5 \mathrm{mM}$ BATB + DCE $\mid 10 \mathrm{mM} \mathrm{LiCl}+62 \mathrm{pM}$ OVA-liposomes (hydrated by $10 \mathrm{mM} \mathrm{DAHCl})|\mathrm{AgCl}| \mathrm{Ag}$ 


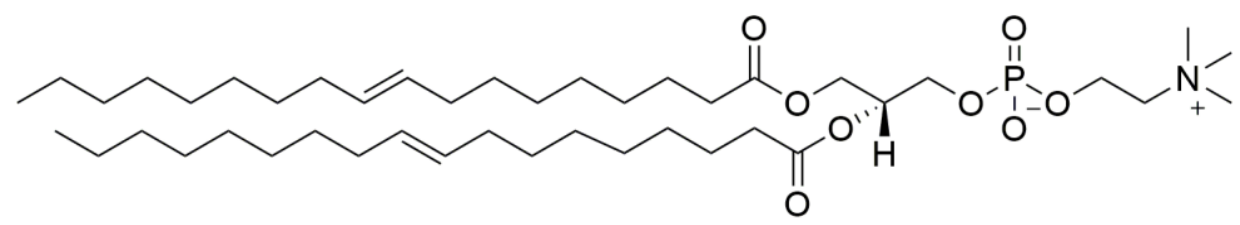

Figure S1. Chemical structure of 1,2-dioleoyl-sn-glycero-3-phosphocholine (DOPC).
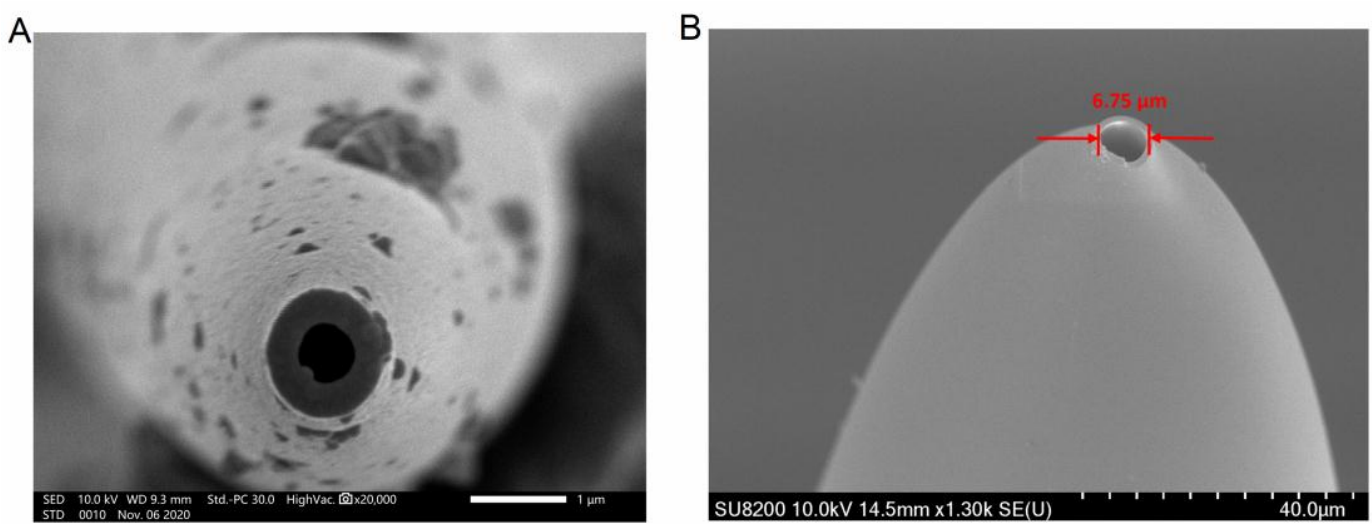

Figure S2. SEM images of (A) a $600 \mathrm{~nm}$ i.d. sub-micropipette pulled by a PC-100 puller with parameters detailed in Table S1 and (B) a typical micropipette used for electrochemical collisional experiments, i.d. $=6.75 \mu \mathrm{m}$, pulled by a P-2000 laser puller with parameters detailed in Table S2. 


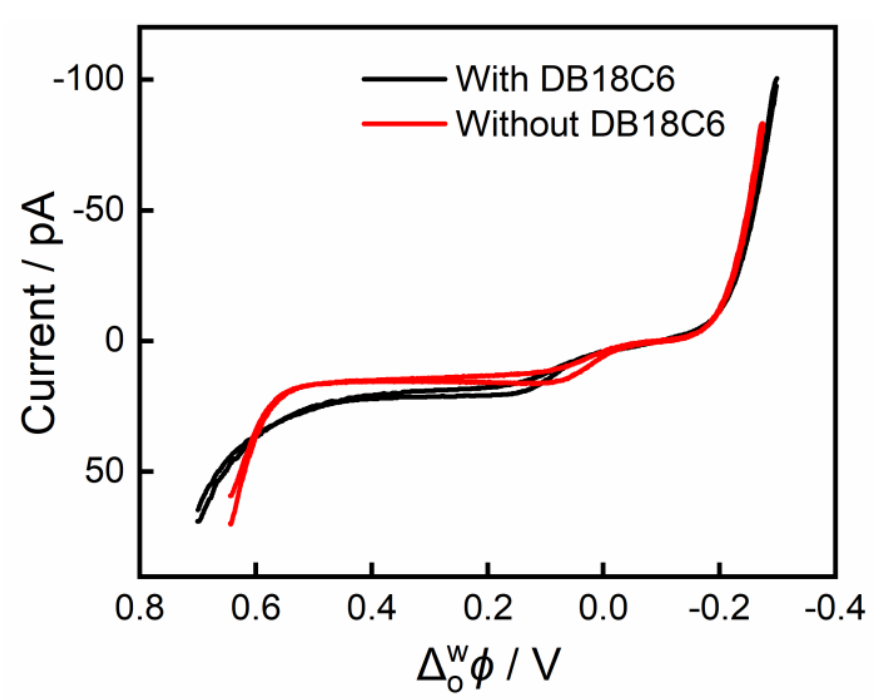

Figure S3. CVs (scan rate: $20 \mathrm{mV} \mathrm{s}^{-1}$ ) recorded at a micro-ITIES (i.d. $=600 \mathrm{~nm}$ ), in which the aqueous phase was $10 \mathrm{mM} \mathrm{LiCl}+2 \mathrm{mM} \mathrm{TEACl}$ and without ion-contained liposomes, and the organic phase was $5 \mathrm{mM}$ BATB with (black trace) or without (red trace) $0.5 \mathrm{mM}$ DB18C6 in 1,2-dichloroethane (DCE). Note that the potential was converted to the Galvani potential scale, based on CV measurement of the reversible half-wave potential of the TEA ${ }^{+}$ion transfer $(0.019$ $\mathrm{V}$ at the $\mathrm{H}_{2} \mathrm{O} / \mathrm{DCE}$ interface, cf. Electrochimica Acta 1990, 35, 1173-1175).

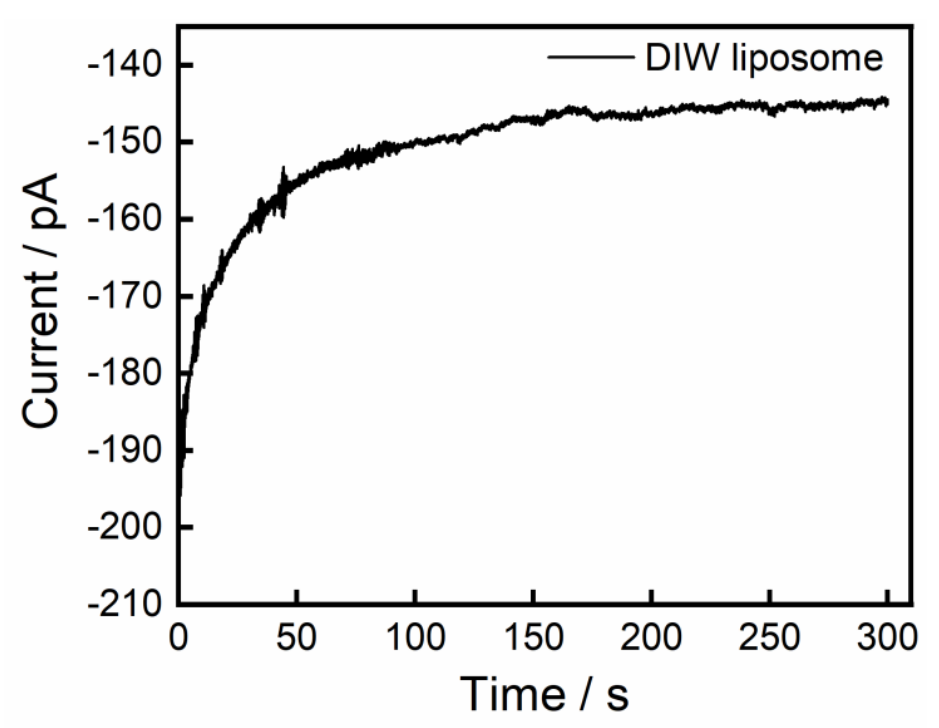

Figure S4. Representative $i-t$ curve for micro-ITIES (i.d. $=8.2 \mu \mathrm{m}$ ) collisional experiments recorded at $+0.6 \mathrm{~V}$ vs. $\mathrm{Ag} / \mathrm{AgCl}$ with water-loaded liposomes. The aqueous supporting electrolyte inside the micropipette was $10 \mathrm{mM} \mathrm{LiCl}$, the organic phase was composed of $5 \mathrm{mM}$ BATB + 0.5 mM DB18C6 in DCE. 
A

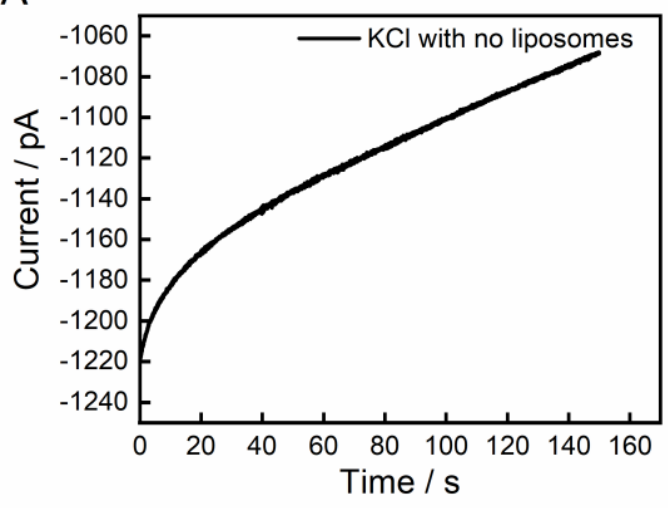

B

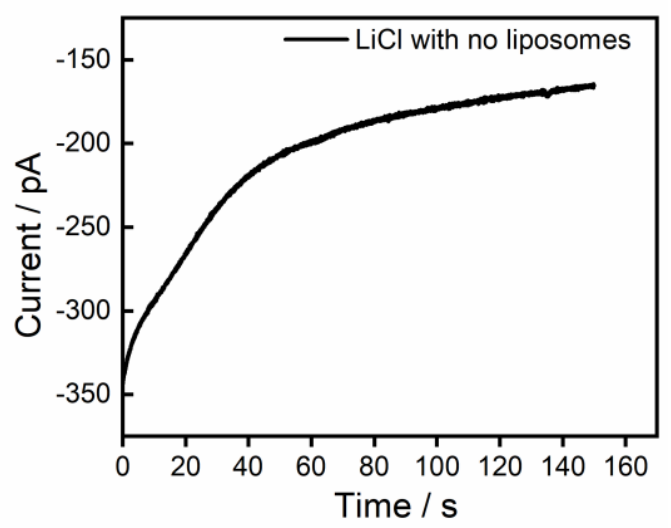

Figure S5. Representative $i-t$ curves for micro-ITIES (i.d. $=6.5$ and $7.7 \mu \mathrm{m}$ for panels A and $\mathrm{B}$, respectively) collisional experiments recorded at $+0.6 \mathrm{~V}$ vs. $\mathrm{Ag} / \mathrm{AgCl}$ in the absence of liposomes but with (A) $10 \mathrm{mM} \mathrm{KCl}$ or with (B) $10 \mathrm{mM} \mathrm{LiCl}$ in the aqueous phase. The organic phase was $5 \mathrm{mM}$ BATB $+0.5 \mathrm{mM}$ DB18C6 in DCE.

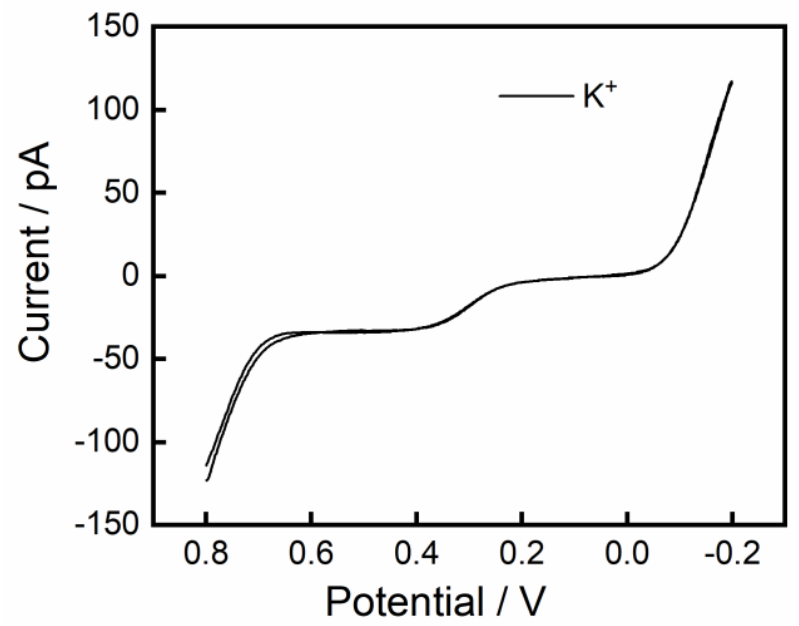

Figure S6. CV (scan rate: $20 \mathrm{mV} \mathrm{s}^{-1}$ ) recorded at a micro-ITIES (i.d. $=600 \mathrm{~nm}$ ), in which the aqueous phase was $10 \mathrm{mM} \mathrm{KCl}$ without ion-contained liposomes, and the organic phase was 5 mM BATB + 0.5 mM DB18C6 in DCE. 


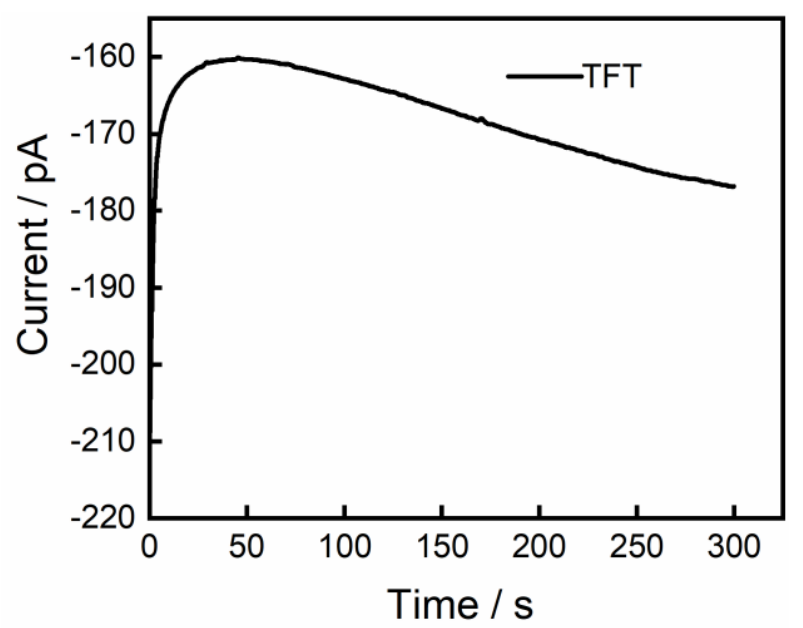

Figure S7. Representative $i-t$ curve for a micro-ITIES (i.d. $=6.5 \mu \mathrm{m})$ collisional experiment recorded at $+0.6 \mathrm{~V}$ vs. $\mathrm{Ag} / \mathrm{AgCl}$, in which the aqueous phase was $\mathrm{K}^{+}$-loaded liposomes suspended in $10 \mathrm{mM} \mathrm{LiCl}$, and the organic phase was $5 \mathrm{mM}$ BATB $+0.5 \mathrm{mM}$ DB18C6 in TFT.

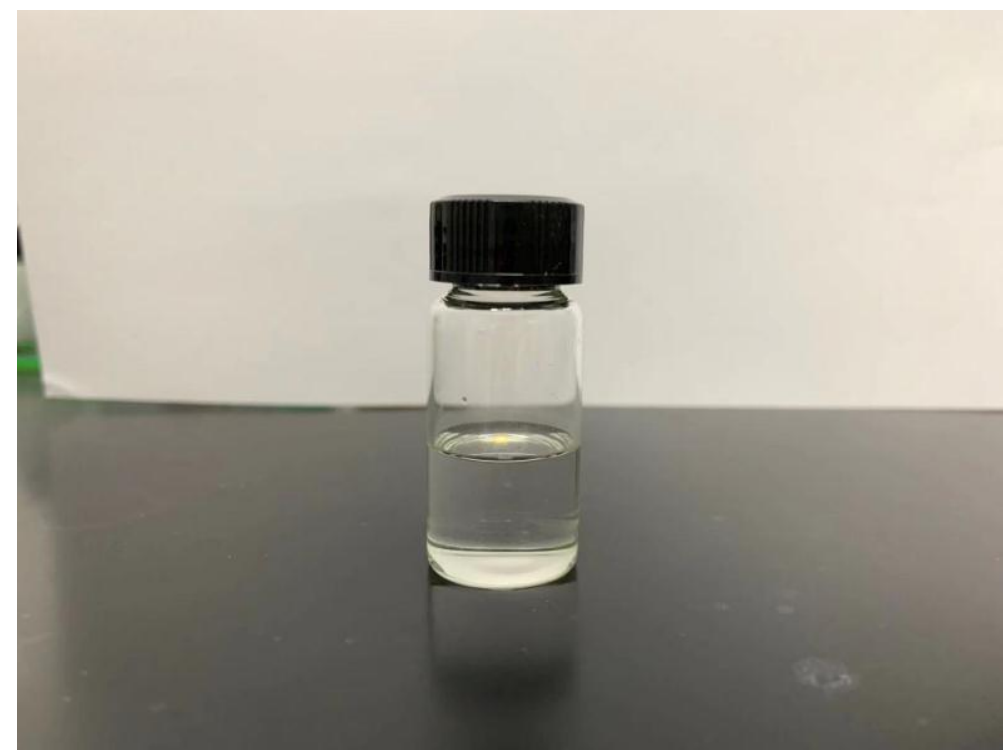

Figure S8. Photo of the $5 \mathrm{~mL}$ DCE dissolving with $7 \mathrm{mg}$ of DOPC. 


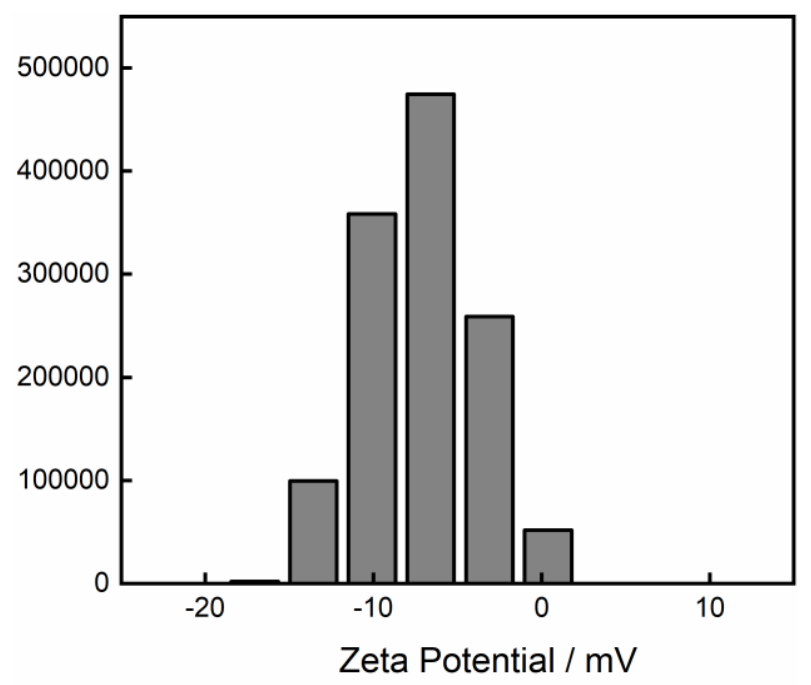

Figure S9. Histograms of the zeta potential of potassium-loaded liposomes suspended in 10 $\mathrm{mM} \mathrm{LiCl}$ as determined by DLS.

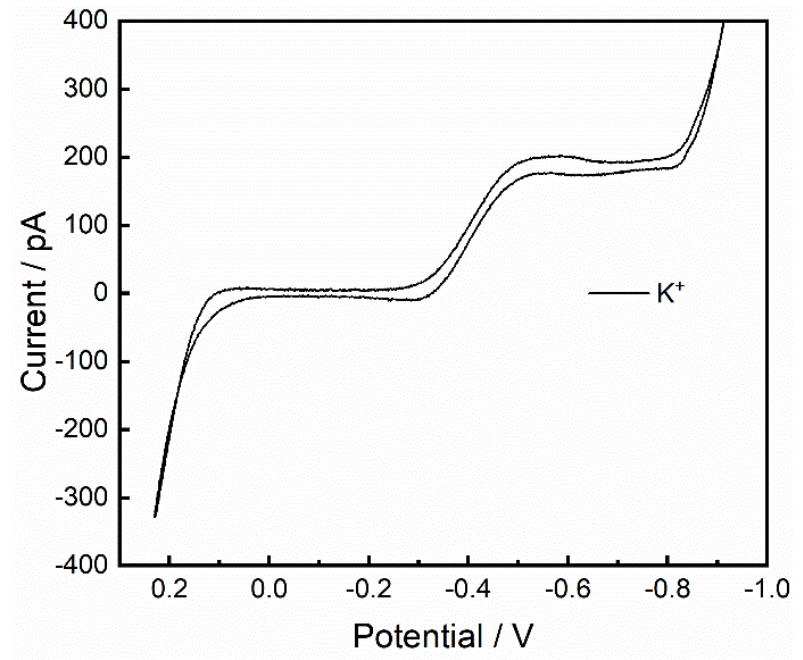

Figure S10. CV (scan rate: $20 \mathrm{mV} \mathrm{s}^{-1}$ ) recorded at a micro-ITIES (i.d. $=1.6 \mu \mathrm{m}$ ), in which the aqueous phase was $10 \mathrm{mM} \mathrm{LiCl}$ and $0.5 \mathrm{mM} \mathrm{KCl}$ without ion-contained liposomes outside the pipette, and the organic phase was $5 \mathrm{mM}$ BATB $+10 \mathrm{mM}$ DB18C6 in DCE inside the pipette. 
A

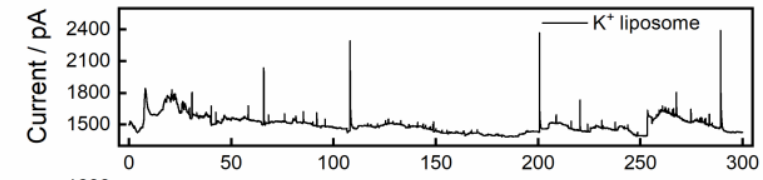

B

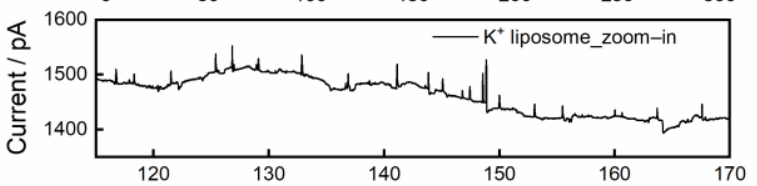

C
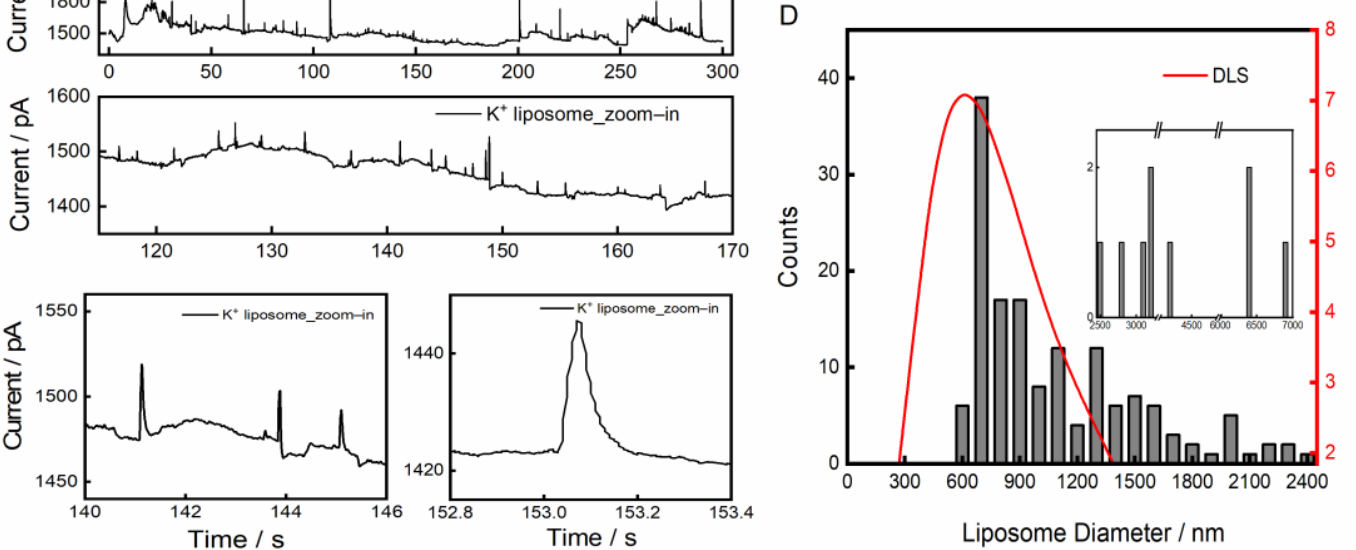

Figure S11. (A) Representative $i-t$ curve recorded at $-0.6 \mathrm{~V}$ vs. $\mathrm{Ag} / \mathrm{AgCl}$ with Cell S-I for collisions of potassium-loaded liposomes onto a micro-ITIES supported at the orifice of a 6.3 $\mu \mathrm{m}$-i.d. micropipette. The data was sampled every $5 \mathrm{~ms}$. (B-C) Zoom-in ranges with different resolutions of $115-170 \mathrm{~s}, 140-146 \mathrm{~s}$, and $152.8-153.4 \mathrm{~s}$ of the $i-t$ curve shown in panel A. (D) Comparison of the liposome size distribution obtained by electrochemical collision detection (gray histogram) and that measured by DLS (red trace).

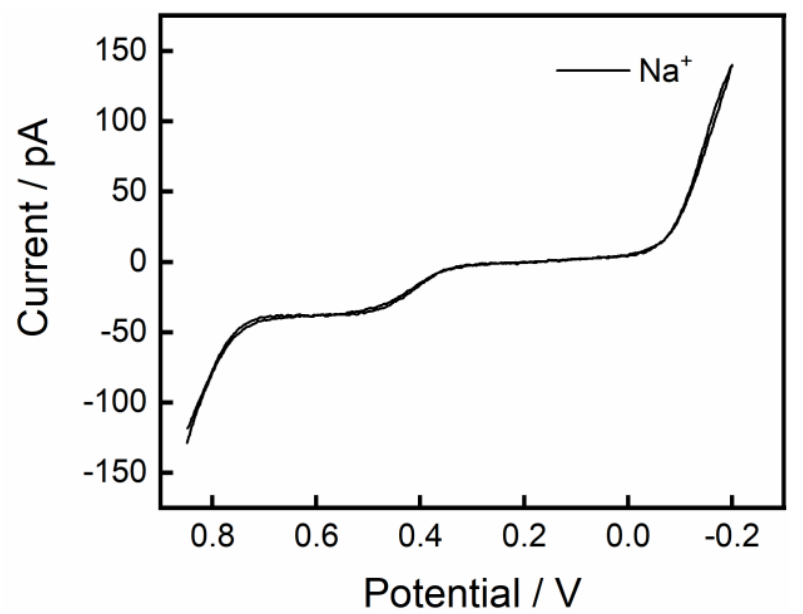

Figure S12. CV (scan rate: $20 \mathrm{mV} \mathrm{s}^{-1}$ ) recorded at a micro-ITIES (i.d. $=600 \mathrm{~nm}$ ), in which the aqueous phase was $10 \mathrm{mM} \mathrm{NaCl}$ without ion-contained liposomes, and the organic phase was $5 \mathrm{mM}$ BATB + $0.5 \mathrm{mM}$ DB18C6 in DCE. 
A

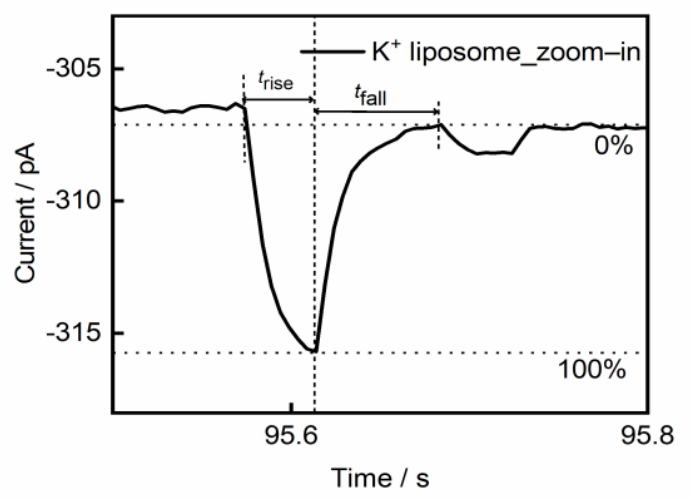

B

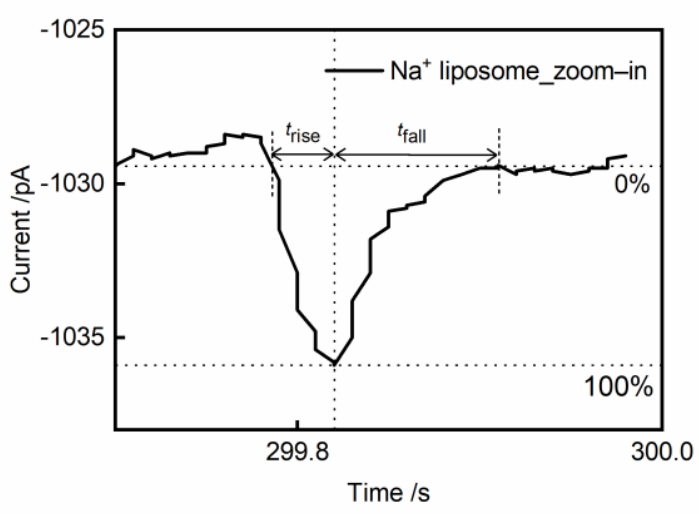

Figure S13. Typical current spike associated with a liposome loaded with either (A) potassium ion or (B) sodium ion. The micro-ITIES has i.d. $=6.4$ and $10 \mu \mathrm{m}$ for panels A and B, respectively; the other parameters were detailed in Figures 2 and 3 in the main text.

A

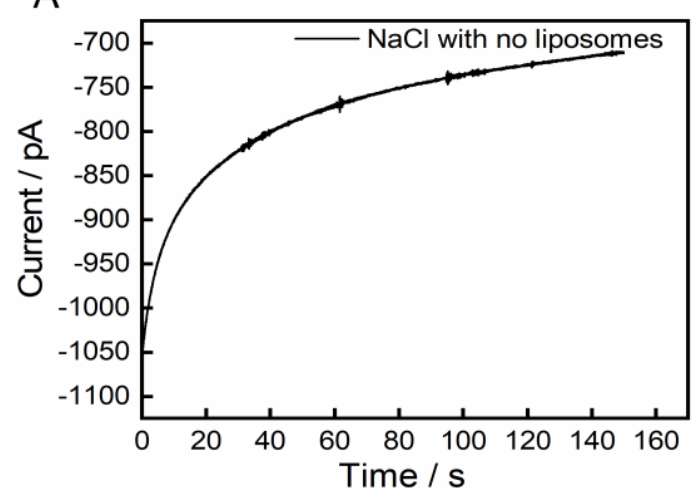

B

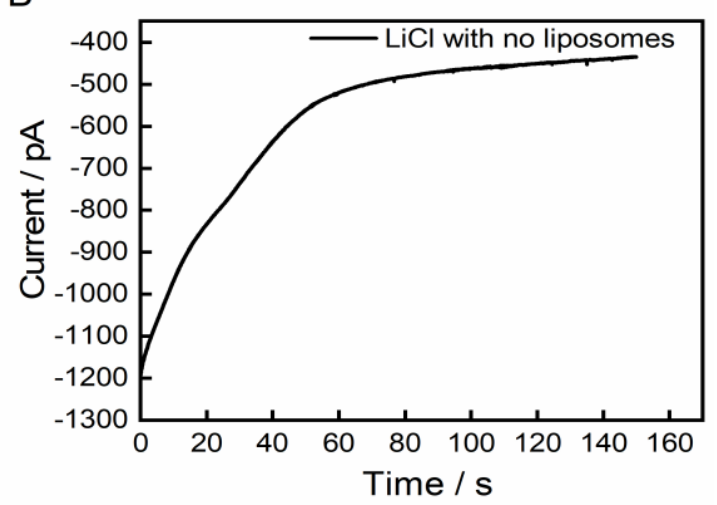

Figure S14. Representative $i-t$ curves for micro-ITIES (i.d. $=9.0$ and $6.7 \mu \mathrm{m}$ for panels A and $\mathrm{B}$, respectively) collisional experiments recorded at $+0.75 \mathrm{~V} \mathrm{vs}$. $\mathrm{Ag} / \mathrm{AgCl}$, in which the aqueous phase was either (A) $10 \mathrm{mM} \mathrm{NaCl}$ or (B) $10 \mathrm{mM} \mathrm{LiCl}$ in the absence of liposomes, and the organic phase was $5 \mathrm{mM}$ BATB $+0.5 \mathrm{mM}$ DB18C6 in DCE. 
A

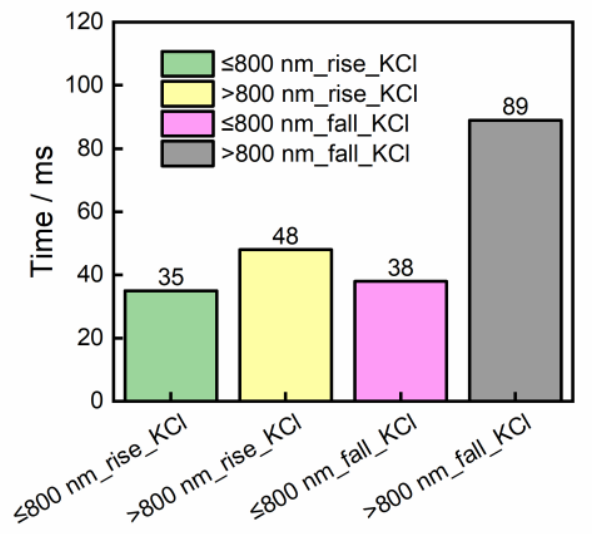

B

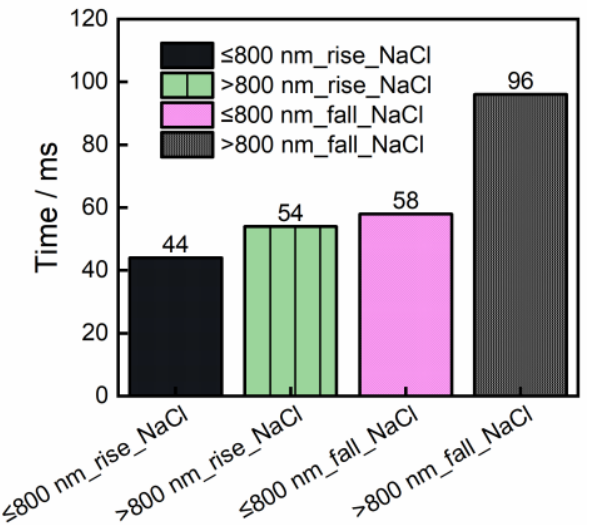

Figure S15. Histograms of $t_{\text {rise }}$ and $t_{\text {fall }}$ of collisions obtained from different-sized (A) potassium ion-loaded liposomes and (B) sodium ion-loaded liposomes. The other experimental conditions were detailed in the captions of Figures 2 and 3 in the main text.

A

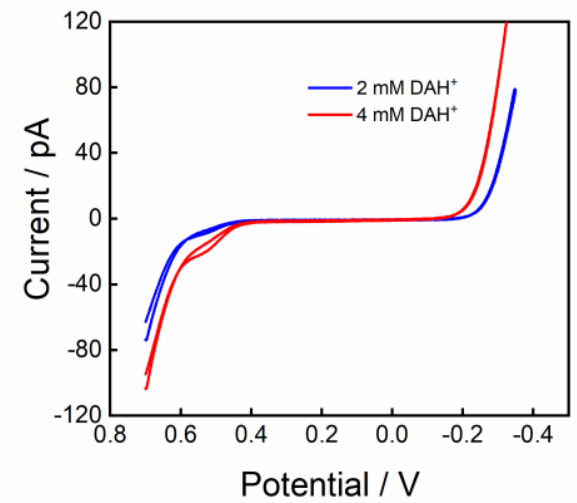

B

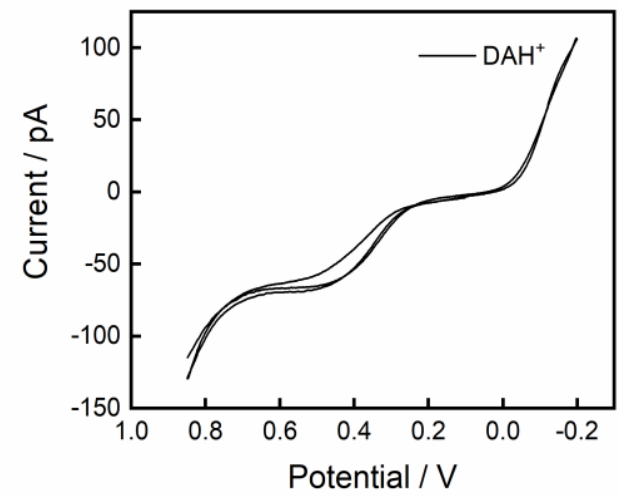

Figure S16. (A) CVs (scan rate: $20 \mathrm{mV} \mathrm{s}^{-1}$ ) recorded at a micro-ITIES (i.d. $=600 \mathrm{~nm}$ ), in which the aqueous phase was $10 \mathrm{mM} \mathrm{LiCl}$ with either 2 (blue trace), or 4 (red trace) mM DAHCl without ion-contained liposomes, and the organic phase was $5 \mathrm{mM}$ BATB in DCE. (B) CV (scan rate: $20 \mathrm{mV} \mathrm{s}^{-1}$ ) recorded at a micro-ITIES (i.d. $=600 \mathrm{~nm}$ ), in which the aqueous phase was $10 \mathrm{mM} \mathrm{DAHCl}$ without ion-contained liposomes, and the organic phase was $5 \mathrm{mM}$ BATB +0.5 mM DB18C6 in DCE. 
A

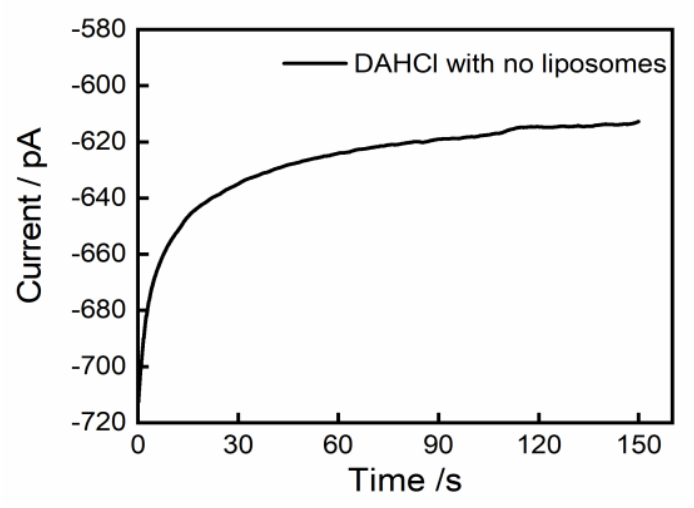

B

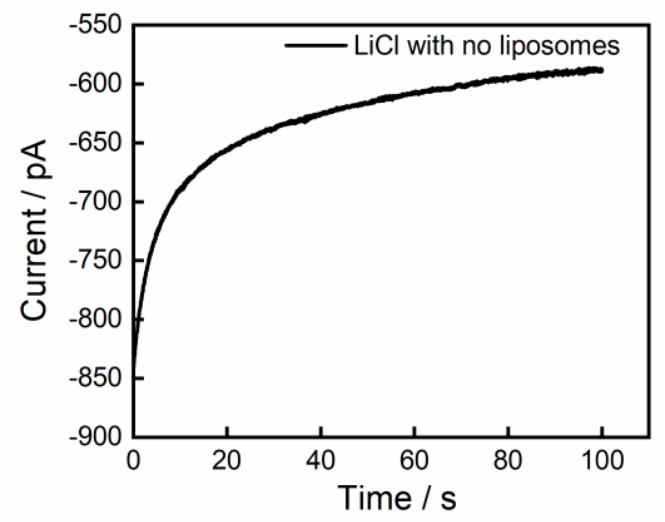

Figure S17. Representative $i-t$ curves for micro-ITIES (i.d. $=5.4$ and $7.5 \mu \mathrm{m}$ for panels A and $\mathrm{B}$, respectively) collisional experiments recorded at $+0.85 \mathrm{~V}$ vs. $\mathrm{Ag} / \mathrm{AgCl}$, in which the aqueous phase was either (A) $10 \mathrm{mM} \mathrm{DAHCl}$ or (B) $10 \mathrm{mM} \mathrm{LiCl}$ in the absence of liposomes, and the organic phase was $5 \mathrm{mM}$ BATB $+0.5 \mathrm{mM}$ DB18C6 in DCE.

A

B
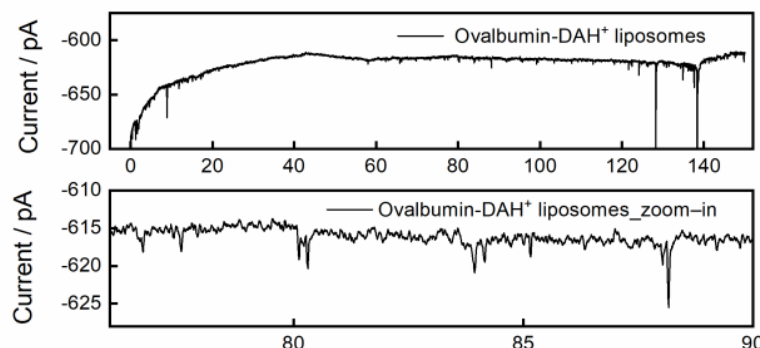

C
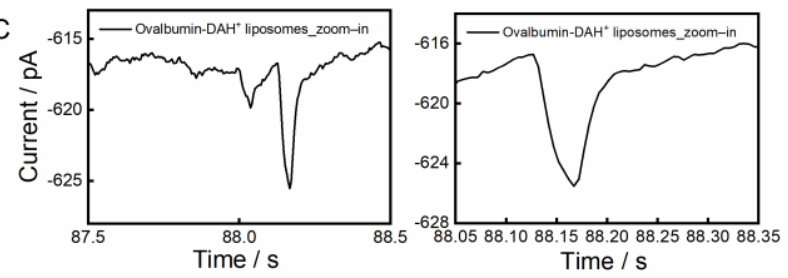

$\mathrm{D}$

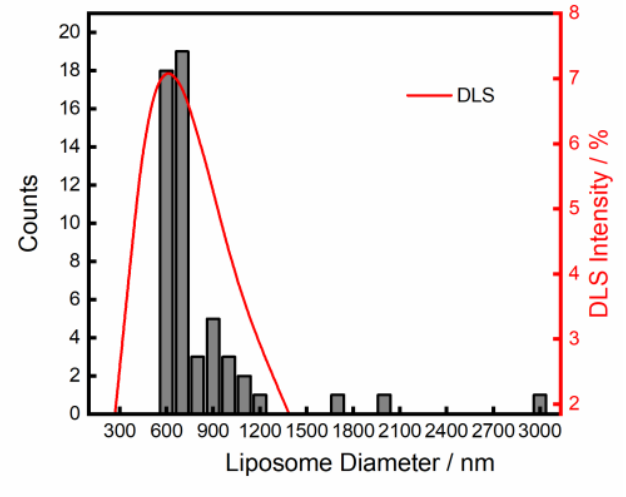

Figure S18. (A) Representative $i-t$ curve recorded at $+0.78 \mathrm{~V}$ vs. $\mathrm{Ag} / \mathrm{AgCl}$ with Cell S-II for collisions of $\mathrm{DAH}^{+}$-loaded ovalbumin-decorated liposomes at a micro-ITIES supported at the orifice of a $8.0 \mu \mathrm{m}$-i.d. micropipette. The data was sampled every $5 \mathrm{~ms}$. (B-C) Zoom-in ranges with different resolutions of 76-90 s, 87.5-88.5 s, and 88.05-88.35 s of the $i^{-} t$ curve shown in panel A. (D) Comparison of the liposome size distribution obtained by electrochemical collision detection (gray histogram) and that measured by DLS (red trace). 

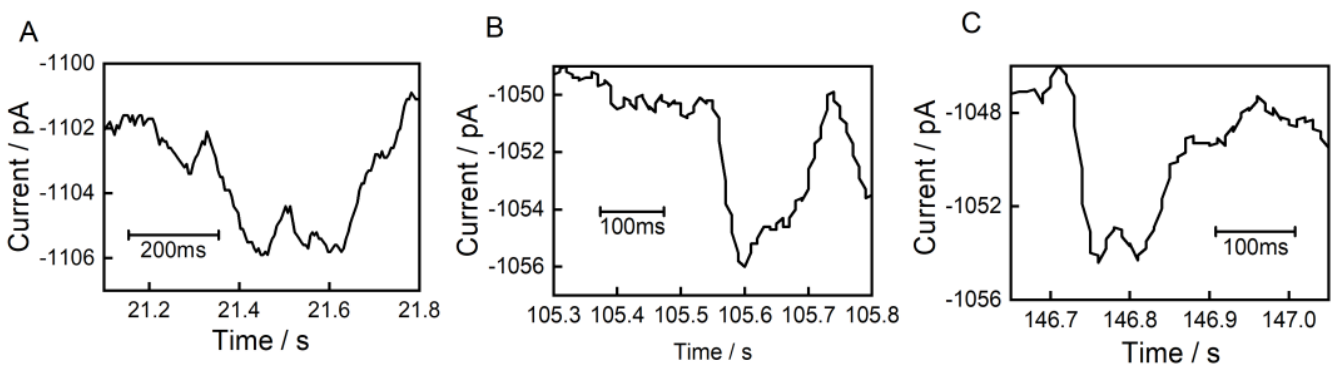

Figure S19. (A-C) More experimental results of observed multiplet events for sodium-ion loaded liposomes. The other experimental conditions were detailed in the caption of Figure 3 in the main text.
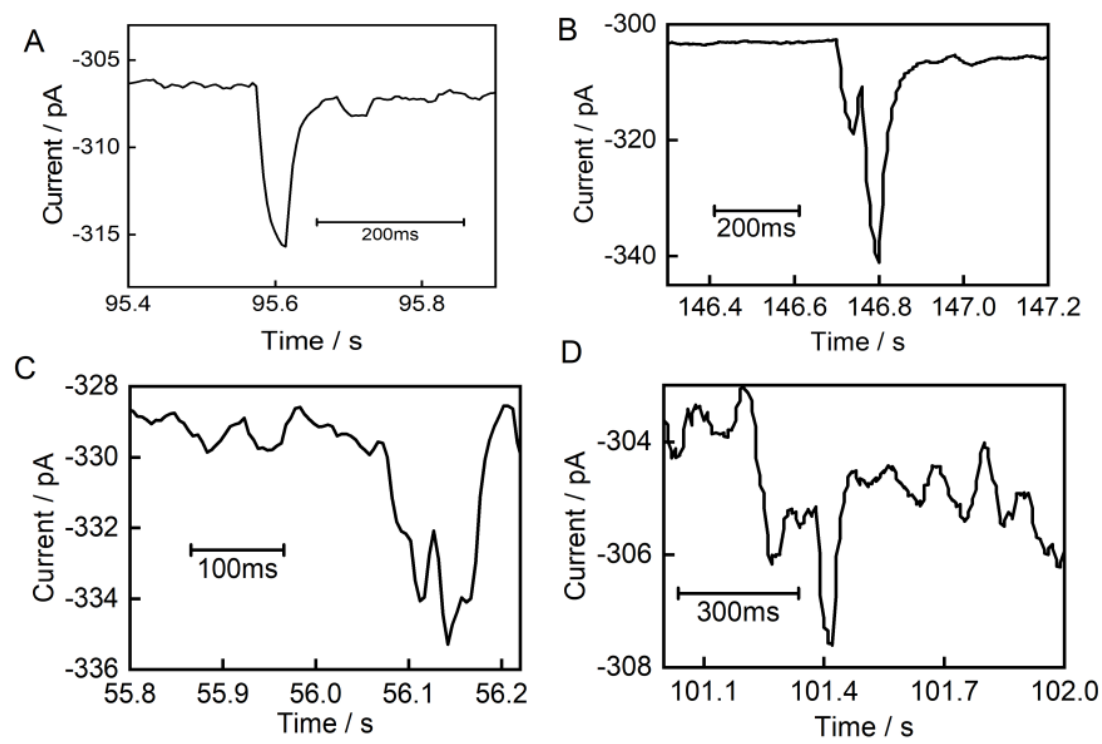

Figure S20. More experimental results of observed (A) singlet, (B) doublet, and (C-D) multiplet events for potassium-ion loaded liposomes. We stressed here that there was another category of multiplet events besides what we have introduced for the results of Figure 5 and related discussions in the main text. When the size of the pore opening increased over time during multiple flickering events, the current feature was expected as that shown in Figure S20 C,D, which was just the opposite of the pore changing process as shown in Figure 5D in the main text. In summary, the singlet event was the most common one with $95 \%$ occurrence frequency, the doublet event had $1 \%$ occurrence frequency, and the multiplet event occurred with $4 \%$ occurrence frequency. The other experimental conditions were detailed in the caption of Figure 2 in the main text. 

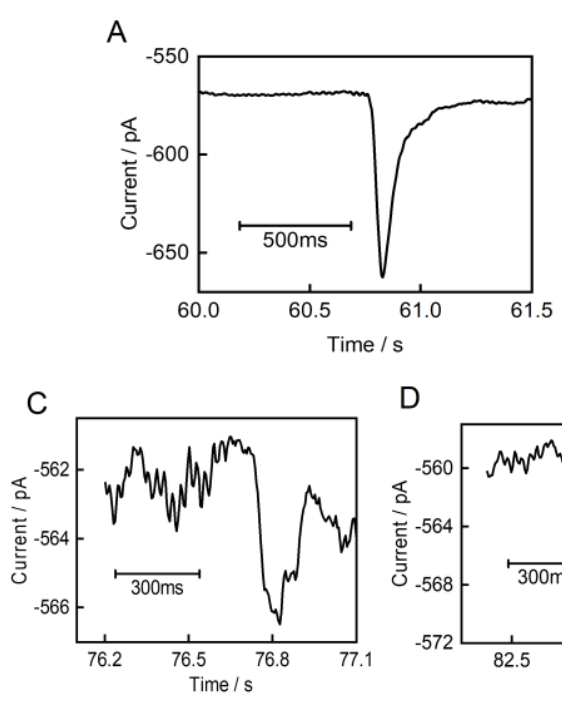

B
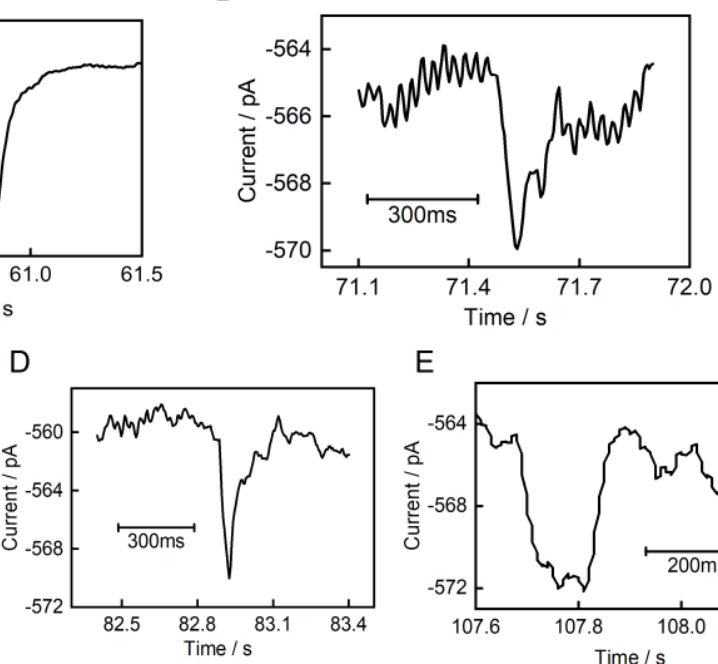

$\mathrm{E}$

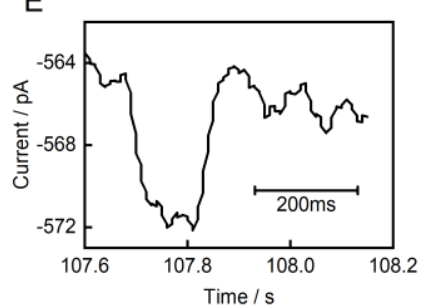

Figure S21. More experimental results of observed (A) singlet, (B) doublet, and (C-E) multiplet events for DAHCl-loaded liposomes. In summary, the singlet event was the most common one with $91 \%$ occurrence frequency, the doublet event had $2 \%$ occurrence frequency, and the multiplet event occurred with $7 \%$ occurrence frequency. The other experimental conditions were detailed in the caption of Figure 4 in the main text. 